\title{
Phytochemical Screening of Some Spices Used as Condiment in Kano, North western Nigeria
}

\author{
Ali $\mathbf{M}^{1 *}$, Nas F $\mathrm{S}^{2}$, Yahaya $\mathrm{A}^{1}$ and Ibrahim $\mathrm{IS}^{3}$ \\ ${ }^{1}$ Microbiology Department, Kano University of Science and Technology, Nigeria \\ ${ }^{2}$ Department of Biological Science, Bayero University Kano, Nigeria \\ ${ }^{3}$ Department of Pharmaceutical Technology, School of Technology, Nigeria
}

\section{Research Article}

Volume 2 Issue 1

Received Date: January 15, 2018

Published Date: January 29, 2018

*Corresponding author: Muhammad Ali, Microbiology Department, Kano University of Science and Technology Wudil Kano, Nigeria, E-mail: alimuhd4real@gmail.com

\section{Abstract}

Spices have been added to foods since ancient times, not only as flavouring agent, but also as food preservatives and folk medicines. The study was aimed to screened for qualitative and quantitative bioactive constituents of aqueous extract of seven commonly used spices in Kano, North western Nigeria; namely Ginger (Zingiber officinale), onion (Allium cepa), Garlic Allium sativa, Pepper mint (Mentha piperita) Tea bush (Ocimum gratissimum), Black pepper (Piper nigrum) and Clove (Syzygium aromaticum). The qualitative phytochemical screening of these spices extracts confirm the presence of various phytochemicals like alkaloids, phenol, glycosides, terpenoids, flavonoids, saponin, anthraquinone, reducing sugar, steroids and tannins.

The quantitative phytochemical screening of the aqueous extract of the studied spices revealed that alkaloids was found to be the most abundant phytochemical in all the spices. Zingiber officinale (12.30\%) Allium cepa (11.30\%), Allium sativa (7.20\%), 0. gratissimum (10.7\%), S. aromaticum (9.60\%), P. nigrum bird pepper (13.10\%) while absent in Mentha piperita. Flavonoid tannin and saponin are available at some extend in most of the spices. The spices were potential sources of phytochemicals which could encourage their use as dietary Supplements in order to maintain and promote healthy life.

Keywords: Spices; Phytochemical; Ginger; Garlic; Onion; Clove

\section{Introduction}

Natural products have been an integral part of ancient traditional medicine systems, e.g. Chinese, Ayurvedic and Egyptian [1]. Over the years, they have assumed a very central stage in modern civilization as natural source of chemotherapy as well as amongst scientist in search for alternative sources of drugs. According to the World Health Organization [2], a medicinal plant is any plant which in one or more of its organs, contains substances that can be used for therapeutic purposes, or which are precursors for chemo-pharmaceutical semi synthesis [2]. Such a plant will have its parts including leaves, roots, rhizomes, stems, barks, flowers, fruits, grains or seeds, employed in the control or treatment of a disease condition and therefore contains chemical components that are medically active [3]. Phytochemicals are bioactive chemicals of plant origin. They are regarded as secondary metabolites because the plant that manufactures them may have little need for them. They 
are naturally synthesized in all parts of the plant body; bark, leaves stem, root, flower, fruits, seeds, etc. i.e. any part of the plant body may contain active components Spices, which include leaves (coriander, pepper mint), buds (clove), bulbs (garlic, onion), fruits (red chili, black pepper), stem (cinnamon), rhizomes (ginger) and other plant parts, have been defined as plant substances from indigenous or exotic origin, aromatic or with strong taste, used to enhance the taste of foods [4,5]. Spices are products of plants (seeds, kernels, bulbs, stalk, roots, fruits, bark, leaves, pods or buds) which are used in various forms such as fresh, ripe, dried, broken or powdered mostly to contribute to colour, taste, aroma, flavour and pungency of food Spices are widely used as condiments and ingredients in food preparation [6,7]. In Nigeria, some spices are useful in the preparation of certain soups which are delicacies and also recommended for rapid relief of ailments such as cold, malaria fever, etc [8]. These spices are also said to be therapeutically useful in the management of stomach ache, leprosy, cough, and loss of appetite, rheumatoid pain, convulsion and inflammation [9].

There is an increasing interest both in the industry and in scientific research for spices and aromatic herbs because of their strong antioxidant and antimicrobial properties, which exceed many currently used natural and synthetic antioxidants. These properties are due to many substances, including some vitamins, flavonoids, terpenoids, carotenoids, phyto estrogens, minerals, etc. and render spices and some herbs or their antioxidant components as preservative agents in food [10]. The study was aimed to evaluate the phyto chemical composition of seven selected spices widely use in Kano, Northwestern Nigeria namely Zingiber officinale, Allium cepa, Allium sativa, Mentha piperita, Ocimum gratissimum, Piper nigrum and Syzygium aromaticum.

\section{Materials and Methods}

\section{Plant Materials}

Fresh rhizomes of Zingiber officinale (Family: Zingiberaceae), bulbs of Allium cepa (Family: Amaryllidaceae), and Allium sativa (Family Amaryllidaceae), leaves of Mentha piperita (Family: Lamiaceae) and Ocimum gratissimum (Family: Lamiaceae) and seeds of Piper nigrum (Family: Piperaceae) and buds of Syzygium aromaticum (Family: Myrtaceae) were purchased from Rimi Market in Kano city, Nigeria. The plant materials were identified in Department of Pharmaceutical Technology, School of Technology Kano, Nigeria (Table1).

\begin{tabular}{|c|c|c|c|c|}
\hline Family name & Botanical name & Common name & Local name & Part used \\
\hline Amaryllidaceae & Allium cepa & Onion & Albasa & Bulbs \\
\hline Amaryllidaceae & Allium sativa & Garlic & Tafarnuwa & Bulbs \\
\hline Lamiaceae & Mentha piperita & Pepper mint & Na'a na'a & Leaves \\
\hline Lamiaceae & Ocimum gratissimum & Tea bush & Doddoya & Leaves \\
\hline Myrtaceae & Syzygium aromaticum & Clove & Kanumfari & Buds \\
\hline Piperaceae & Piper nigrum & Black pepper & Masora & Seeds \\
\hline Zingiberaceae & Zingiber officinale & Ginger & Citta & Rhizomes \\
\hline
\end{tabular}

Table 1: Family, botanical, common and local names of the plants used

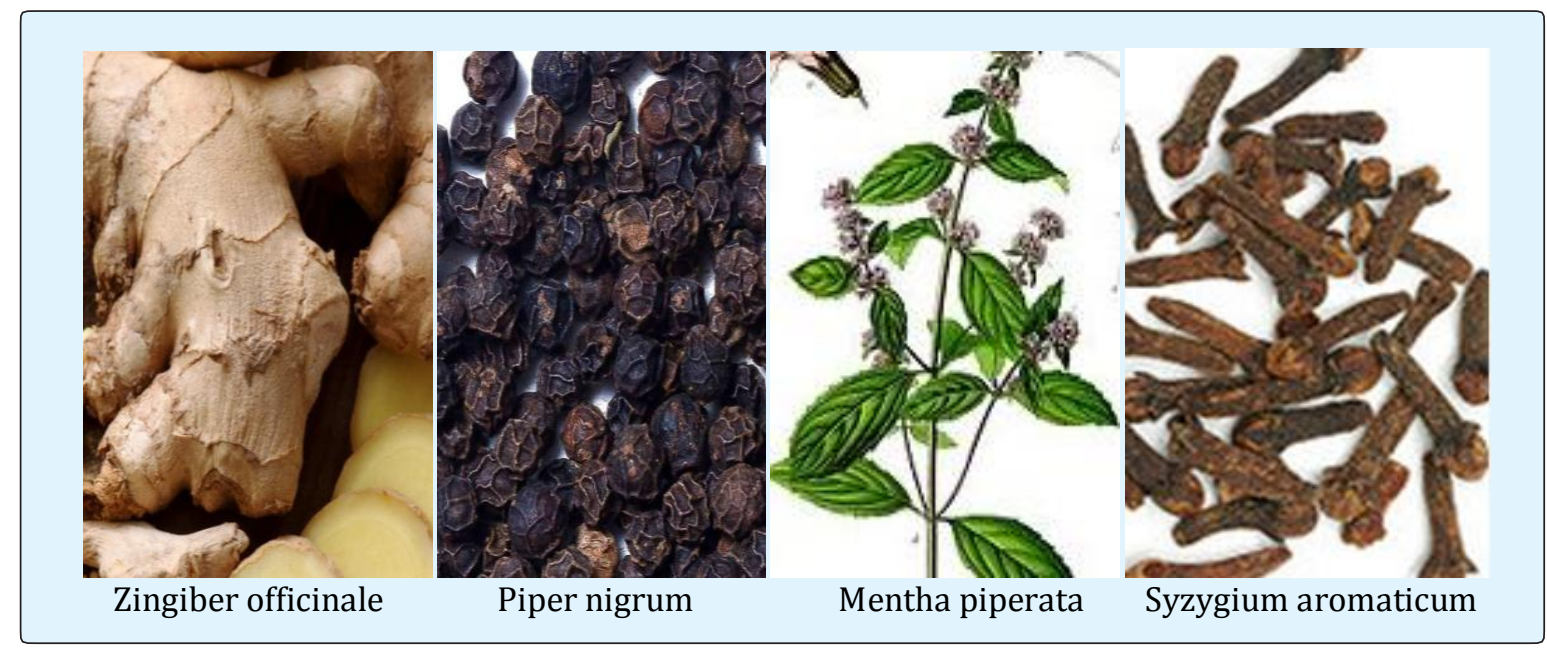

Ali M, et al. Phytochemical Screening of Some Spices Used as Condiment in Kano, North western Nigeria. Pharm Res 2018, 2(1): 000150. 


\section{Open Access Journal of Pharmaceutical Research}

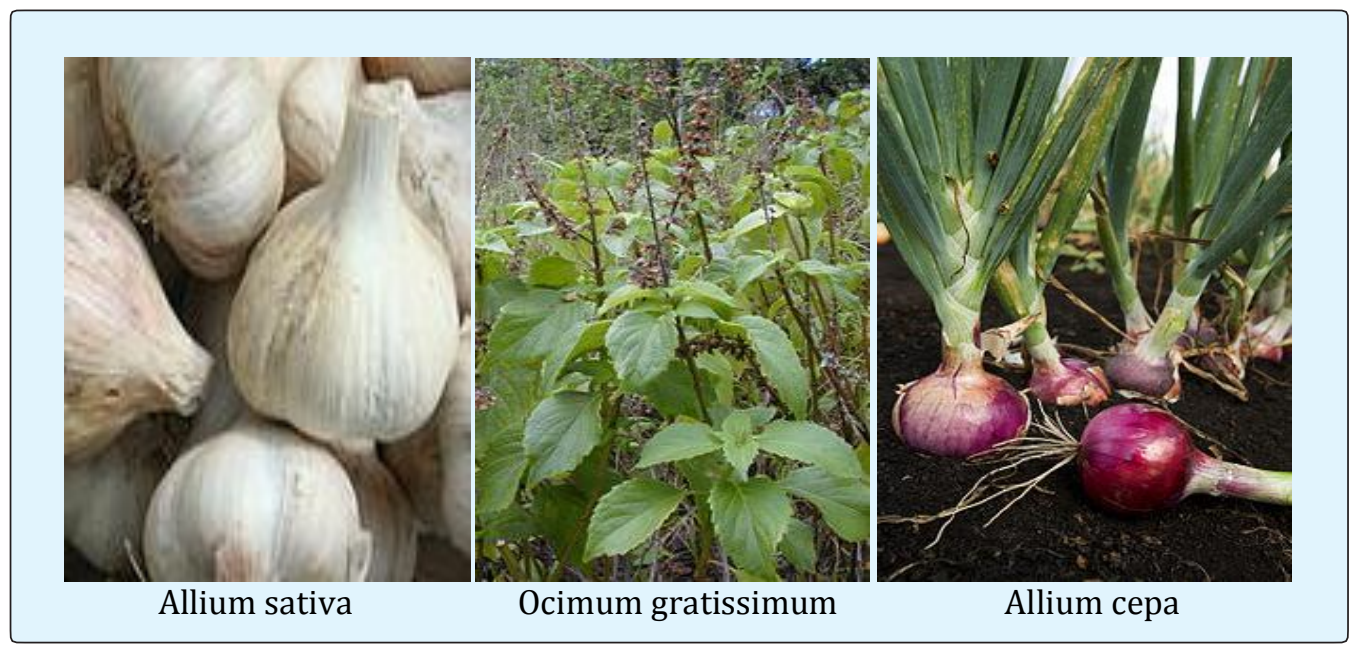

\section{Preparation of Extracts}

The collected rhizome, bulbs, leaves, buds and seeds of the plant materials were washed with distilled water, air dried for two weeks and grounded into fine powder using sterile pestle and mortar under laboratory condition. Fifty (50) grams of each powder was mixed with $500 \mathrm{ml}$ of Distilled water in a sterile conical flask and stand for 3 days with intermittent shaking. The mixtures were filtered using filter paper and concentrated in water bath at $600^{\circ} \mathrm{C}$ for 3 hours. Each extract was kept in a sterile container and refrigerated at $40^{\circ} \mathrm{C}$ for further experiment.

\section{Phytochemical Screening}

The phytochemical screening of the plant materials for various phytochemical constituents such as terpenoids, flavonoids, alkaloids, reducing sugars, steroid, glycoside, phenol, Anthraquinones, saponin and tannin was conducted using standard methods as described by Sofowora A [8] and Trease \& Evans [11].

\section{Quantitative Phytochemical Analysis}

Different methods were used in evaluating the quantity of phytochemical constituents of the plant materials used. Spectrophotometric method was used to determine Terpenoids, tannins, steroids, anthraquinone, and glycosides. Folin-Ciocalteu procedure was used to determine phenol content. Flavonoids, alkaloids and saponins were determined by the methods described by Adeniyi, et al. [12].

\section{Results}

\section{Qualitative Phytochemical Screening}

The phytochemical constituents of aqueous of rhizome of Zingiber officinale, bulb of Allium cepa, and Allium sativa, leaves of Mentha piperita and Ocimum gratissimum and seeds of Piper nigrum and buds of Syzygium aromaticum are tabulated in Table 2.

\begin{tabular}{|c|c|c|c|c|c|c|c|}
\hline Phytochemicals & Z. officinale & A. cepa & A. sativa & M. piperita & O. gratissimum & S. aromaticum & P. nigrum \\
\hline Alkaloids & + & + & + & - & + & + & + \\
\hline Flavonoid & + & + & + & + & + & + & + \\
\hline Glycosides & + & + & + & + & + & - & - \\
\hline Reducing sugar & + & + & + & + & + & - & - \\
\hline Saponin & + & + & + & + & + & + & + \\
\hline Steroids & + & + & + & - & + & + & + \\
\hline Phenols & + & + & + & - & + & + & + \\
\hline Terpenoid & + & + & + & + & + & + & + \\
\hline Anthraquinones & + & + & + & + & + & + & + \\
\hline Tannin & + & + & + & + & + & - & + \\
\hline
\end{tabular}

Key: + = Presence of phytochemical, - = absent of phytochemical

Table 2: The phytochemical constituents of the plant materials 


\section{Open Access Journal of Pharmaceutical Research}

The quantitative phytochemical constituents of aqueous of rhizome of Zingiber officinale, bulb of Allium cepa, and Allium sativa, leaves of Mentha piperita and Ocimum gratissimum and seeds of Piper nigrum and buds of Syzygium aromaticum are tabulated in (Table3). Alkaloids was found to be the most abundant phytochemical in all the spices except M. piperita.

\begin{tabular}{|c|c|c|c|c|c|c|c|}
\hline Phytochemicals & Z. officinale & A. cepa & A. sativa & M. piperita & O. gratissimum & S. aromaticum & P. nigrum \\
\hline Alkaloids & $12.15 \pm 0.04$ & $11.30 \pm 0.09$ & $7.20 \pm 0.05$ & $0.00 \pm 0.00$ & $10.70 \pm 0.06$ & $9.60 \pm 0.12$ & $13.10 \pm 0.11$ \\
\hline Flavonoid & $4.50 \pm 0.02$ & $4.00 \pm 0.01$ & $2.18 \pm 0.03$ & $3.85 \pm 0.05$ & $2.90 \pm 0.03$ & $3.00 \pm 0.09$ & $5.25 \pm 0.10$ \\
\hline Glycosides & $0.08 \pm 0.01$ & $1.80 \pm 0.02$ & $0.05 \pm 0.00$ & $1.00 \pm 0.01$ & $0.08 \pm 0.01$ & $0.00 \pm 0.00$ & $0.00 \pm 0.00$ \\
\hline Reducing sugar & $0.10 \pm 0.01$ & $3.62 \pm 0.05$ & $0.08 \pm 0.01$ & $0.90 \pm 0.01$ & $0.05 \pm 0.00$ & $0.00 \pm 0.00$ & $0.00 \pm 0.00$ \\
\hline Saponin & $1.20 \pm 0.01$ & $5.30 \pm 0.03$ & $4.30 \pm 0.02$ & $1.25 \pm 0.01$ & $2.80 \pm 0.01$ & $3.70 \pm 0.00$ & $0.06 \pm 0.00$ \\
\hline Steroids & $0.07 \pm 0.00$ & $0.05 \pm 0.00$ & $0.00 \pm 0.00$ & $0.00 \pm 0.00$ & $0.05 \pm 0.01$ & $1.80 \pm 0.04$ & $1.27 \pm 0.01$ \\
\hline Phenols & $0.10 \pm 0.01$ & $0.08 \pm 0.01$ & $0.00 \pm 0.00$ & $0.00 \pm 0.00$ & $0.05 \pm 0.01$ & $0.10 \pm 0.01$ & $0.70 \pm 0.01$ \\
\hline Terpenoid & $0.15 \pm 0.00$ & $0.09 \pm 0.01$ & $0.40 \pm 0.01$ & $2.30 \pm 0.01$ & $0.12 \pm 0.00$ & $1.70 \pm 0.01$ & $0.17 \pm 0.01$ \\
\hline Anthraquinones & $1.20 \pm 0.01$ & $1.30 \pm 0.01$ & $1.40 \pm 0.03$ & $2.60 \pm 0.03$ & $0.80 \pm 0.02$ & $1.20 \pm 0.03$ & $0.90 \pm 0.01$ \\
\hline Tannin & $3.70 \pm 0.04$ & $4.50 \pm 0.02$ & $6.30 \pm 0.03$ & $1.50 \pm 0.01$ & $4.10 \pm 0.05$ & $0.00 \pm 0.00$ & $2.20 \pm 0.03$ \\
\hline
\end{tabular}

Table 3: Phytochemical content of the plants materials

\section{Discussion}

These secondary metabolites contribute significantly towards the biological activities of medicinal plants such as hypo glycemic, anti-diabetic, antioxidant, antimicrobial, anti-inflammatory, anti-carcinogenic, anti-malarial, anti cholinergic, anti-leprosy activities etc [3].

This research work was conducted on the seven selected medicinal plants used as spices in Kano, North western Nigeria to determine the qualitative and quantitative of some phyto chemical present in them. The results shows that phyto chemical constituents of the selected spices include; terpenoids, flavonoids, alkaloids, reducing sugars, steroid, glycoside, phenol, Anthra quinones, saponin and tannin. Several studies were conducted to determine phyto chemical constituents of spices [13-17]. These plants used as food preservatives and folk medicines. So, their value is depend on the phytochemicals they possess [18]. The spices, herbs, plant extracts and their phyto-constituents have been reported for anti-inflammatory, anti diarrheal, antimicrobial, antioxidant and insecticidal activities [19]. According to this study, Alkaloid is present in all the extracts except Mentha piperita extract. Alkaloids comprising a large group of nitrogenous compounds are widely used as cancer chemotherapeutic agents, anaesthetics and Central Nervous Stimulants $[20,21]$. Alkaloids are known to play some metabolic roles and control development in living system [22]. It also interferes with cell division, hence the presence of alkaloids in ginger, clove, onion, garlic and black pepper could account for their use as antimicrobial agents. Aboaba et al. had reported that the antimicrobial properties of substances are desirable tools in food spoilage and food safety [23]. This suggests that the spices extracts which have been confirmed to contain alkaloids may also be useful as preservatives in food. Flavonoid, terpenoid and anthrax quinone are present in all the extract according to this study. Terpenoids have been found to be useful in the prevention and therapy of several diseases, including cancer. Terpenoids are also known to possess antimicrobial, antifungal, antiparasitic, antiviral, anti-allergenic, antispasmodic, anti hyperglycemic, anti inflammatory and immune modulatory properties [24]. Flavonoids are also present in all the extracts as a potent water-soluble antioxidant and free radical scavenger, which prevent oxidative cell damage and also have strong anticancer activity $[25,26]$. It also helps in managing diabetes induced oxidative stress. Saponin and tannin were also present in all the extracts. Saponins protect against hypercholesterolemia and antibiotics properties [27]. In addition, it has been documented that saponins have antitumor, antioxidant and anti-mutagenic activities and can lower the risk of human cancers by inhibiting the growth of cancer cells $[28,29]$. The growth of many fungi, yeast, bacteria and viruses was inhibited by tannins [30]. Tannins are used as antiseptic and this activity is due to presence of the phenolic group. Tannin rich medicinal plants are used as healing agents in a number of diseases. In Ayurveda, formulations based on tannin-rich plants have been used for the treatment of diseases like leucorrhoea, rhinnorhoea and diarrhoea [3]. According to the present study, steroid is present in most of the extracts. Steroids are importance in pharmacy as they possess compounds like sex hormones and can be used for drug production [18]. 


\section{Open Access Journal of Pharmaceutical Research}

The phyto chemical content of the aqueous extract of the studied spices in this study is presented in (Table 3). Alkaloids were found to be the most abundant phyto chemical in all the spices. Zingiber officinale $(12.30 \%)$ Allium cepa (11.30\%), Allium sativa (7.20\%), 0. gratissimum $(10.7 \%)$, S. aromaticum $(9.60 \%)$, P. nigrum bird pepper $(13.10 \%)$ while absent in mentha piperita. Flavonoid tannin and saponin are available at some extend in most of the plants under study.

\section{Conclusion}

The results of this study showed that the selected seven spices consist of many useful phytochemical compounds having important biological properties such phytochemicals include terpenoids, flavonoids, alkaloids, reducing sugars, steroid, glycoside, phenol, Anthraquinones, saponin and tannin. The study also revealed that Alkaloids was the most abundant phytochemical in all the spices except Mentha piperita. Therefore, the above plants extract could be explored for its highest therapeutic efficacy by pharmaceutical companies in order to develop safe drugs for various ailments. It is recommended that effort should be made to exploit the biomedical applications of these spices due to the presence of such bioactive constituents for full utilization.

\section{Acknowledgement}

The authors wish to acknowledge to Technical staff of Departments of Pharmaceutical technology and those of Science Laboratory Technology (SLT), School of Technology Kano for the use of Laboratory facilities.

\section{References}

1. Sarker SD, Nahar L (2007) Chemistry for Pharmacy Students General, Organic and Natural Product Chemistry. John Wiley and Sons 283-359.

2. World Health Organization (WHO) (2004) Use of antibacterials outside human medicine and result and antibacterial resistance in humans. World Health Organization.

3. Doughari JH (2012) Phytochemicals: Extraction Methods, Basic Structures and Mode of Action as Potential Chemotherapeutic Agents.

4. Tiwari R, Das K and Shrivastava DK (2010) Techniques for evaluation of medicinal plant products as antimicrobial agent: Current methods and future trends. J Med Plant Res 4(2): 104-111.
5. Pundir RK, Jain P, and Sharma C (2010) Antimicrobial activity of ethanolic extracts of Syzygium aromaticum and Allium sativum against food associated bacteria and fungi. Ethnobot Leaflets 14: 344-360.

6. Parveen S, Das S, Begum A, Sultana N, Hoque M, et al. (2014) Microbiological quality assessment of three selected spices in Bangladesh. International Food Research Journal 21(4): 1327-1330.

7. Ene-Obong HN, Onuoha NO, Aburime LC, Mbah O (2015) Nutrient compositition phytochemicals and antioxidant activities of some indigenous spices in Southern Nigeria. 11

8. Sofowora A (1993) Medicinal plants and traditional medicine in Africa. Spectrum Books Ltd. 2nd Edn; 289.

9. Valko M, Leibfritz D, Moncol J, Cronin MT, Mazur M et al. (2007) Free radicals and antioxidants in normal physiological functions and human disease. Int J Biochem Cell Biol 39(1): 44-84.

10. Calucci L, Pinzono C, Zandomeneghi M, Capocchi A. (2003) Effects of gamma-irradiation on the free radical and antioxidant contents in nine aromatic herbs and spices. J Agric Food Chem 51(4): 927-934.

11. Trease GE, Evans WC (2002) Phytochemicals. In: Pharmacognosy. 15th ed. Saunders Publishers, London, pp. 42-44, 221- 229, 246- 249, 304-306,331332, 391-393.

12. Adeniyi SA, Orjiekwe CL, Ehiagbonare JE (2009) Determination of alkaloids and oxalates in some selected food samples in Nigeria. Afr J Biotechnol 8(1): 110-112.

13. Harsha N, Sridevi V, Lakshmi C, Rani K, Vani S (2013) Phytochemical Analysis of Some Selected Spices. International Journal of Innovative Research in Science, Engineering and Technology Vol. 2, (11) 6618-6621.

14. Tacouri DV, Deena R, Puchooa D (2013) In vitro bioactivity and phytochemical screening of selected spices used in Mauritian foods. Asian Pac J Trop Dis 3(4): 253-261.

15. Kumaravel S, Alagusundaram K (2014) Antimicrobial Activity and Phytochemical Analysis of Selected Indian Spices. Journal of Pure and Applied Microbiology 8(5): 1-6. 


\section{Open Access Journal of Pharmaceutical Research}

16. Akeem S, Joseph J, Kayode R and Kolawole F. (2016) Comparative phytochemical analysis and use of some Nigerian spices. Croatian Journal of Food Technology, Biotechnology and Nutrition 11(3-4): 145-151.

17. Inas MK, Ahmed AA (2017) Preliminary Phytochemical Screening of Different Solvent Extracts of Some Medicinal plants. Middle East J Appl Sci 7(2): 226-231.

18. Okwu DE (2001) Evaluation of chemical composition of indigenous spices and flavoring agents. Global Journal of Pure and Applied Sciences 7(3): 455-459.

19. Lu M, Yuan B, Zeng M, Chen J (2011) Antioxidant capacity and major phenolic compounds of spices commonly consumed in China. Food Res Int 44(2): 530-536.

20. Noble RL (1990) The discovery of vinca alkaloids chemotherapeutic agents against cancer. Biochem Cell Biol 68(12): 1344-1351.

21. Madziga HA, Sanni S, Sandabe UK (2010) Phytochemical and Elemental Analysis of Acalypha wilkesiana Leaf. Journal of American Science 6(11): 510-514.

22. Edeoga HO, Omobuna G, Uche LC (2006) Chemical composition of Hyotissu aveoleus and Ocimum gratissium hybrids from Nigeria. Afr J Biotechnol 5(10): 892-895.
23. Aboaba 00, Ezeh AR, Anabuike CL (2011) Antimicrobial activities of some Nigerian spices on some pathogens. Agric Biol J N Am 2(8): 1187-1193.

24. Rabi T, Bishayee A (2009). Terpenoids and breast cancer chemoprevention. Breast Cancer Res Treat 115(2): 223-239.

25. Salah N, Miler NJ, Pagange G, Tijburg L, Bolwell GP, et al. (1995) Polyphenolic flavonoids as scavenger of aqueous phase radicals as chain breaking antioxidant. Arch Biochem Broph 322(2): 339-346.

26. Rio DA, Obdululio BG, Casfillo J, Marin FG, Ortuno A (1997) Uses and properties of citrus flavonoids. J Agric Food Chem 45(12): 4505-4515.

27. Amin MM, Sawhney SS, Jassal MS (2013) Qualitative and quanditative analysis of phytochemicals of Taraxacum officinale. Wudpecker J Pham Phamacol 2(1): 1-5.

28. Roa RR, Babu RM, Rao MRV (1995) Saponins as anticarcinogens. J Nutr 125(3): 717-724.

29. Prohp T P, Onoagbe IO (2012) Determination of phytochemical composition of the stem bark of triplochiton scleroxylon $\mathrm{k}$ schum (sterculiaceae) International Journal of Applied Biology and Pharmaceutical Technology 3(2): 68-76.

30. Chung KT, Wong TY, Wei CL, Huang Lin Y (1998) Tannins and human health. Criti Rev Food Sci Nutri 38(6): 421-464. 